\title{
Peduncular Hallucinosis Associated with Ruptured Basilar-Superior Cerebellar Artery Aneurysm
}

\author{
- Case Report-
}

\author{
Yasuhiro HARADA, Hiroshi ISHIMITSU, Ichiro MIYATA, Chiho HONDA \\ and Ken NISHIMOTO
}

Department of Neurosurgery, Iwakuni National Hospital, Iwakuni, Yamaguchi

\begin{abstract}
A 65-year-old female developed peduncular hallucinosis 3 days after rupture of a basilar-superior cerebellar artery aneurysm. There were no neurological deficits except slight anisocoria when she first complained of hallucinations. Vasospasm of the perforating arteries to the upper brainstem, rather than direct brainstem damage caused by the bleeding, was probably the cause. Peduncular hallucinosis is possibly the only localizing sign of ruptured upper posterior circulation aneurysm.
\end{abstract}

Key words: peduncular hallucinosis, basilar-superior cerebellar artery aneurysm

\section{Introduction}

Peduncular hallucinosis was first described by Lhermitte in 1922,4) and was named by Van Bogaert in $1927 .{ }^{6)}$ It is a rare occurrence in patients with a cerebrovascular accident in the midbrain. The hallucinations are vivid, well formed, and always recognized as unreal by the patient. We report a case of a ruptured right basilar-superior cerebellar artery (SCA) aneurysm associated with peduncular hallucinosis.

\section{Case Report}

A 65-year-old female suddenly developed headache and vomiting on May 1,1982 . She was admitted to another hospital, where a lumbar puncture revealed bloody cerebrospinal fluid. She was transferred to our hospital on May 4, 1982.

On admission, she was alert and well oriented. She did not complain of headache and showed no nuchal stiffness. The right pupil was $2.5 \mathrm{~mm}$ and the left was $2.0 \mathrm{~mm}$ in diameter. Both pupils, however, reacted quickly to light. Her visual acuity was $20 / 20$ bilaterally. The visual fields were normal by the confrontation test. No other neurological deficit was observed. A precontrast computed tomographic (CT) scan revealed subarachnoid hemorrhage mainly in the suprasellar cistern, but failed to locate the ruptured aneurysm.

On the 3rd hospital day, she complained of insomnia due to visual hallucinations. She reported that a colorful landscape of mountains, trees, and a river appeared every evening when she closed her eyes. Sometimes people walked around in the scene, but she could hear nothing. She could not tell where it was nor who they were. She did not fear the hallucinations, which she always recognized were unreal. Her only complaint was insomnia because the hallucinations appeared as soon as her eyes were closed. She denied the possibility of a dream, and said, "Even now (it was around 3:00 p.m.), I can see the color of this wooden chest is changing from red to orange, and when I close my eyes, I can see beautiful flowers on the wooden surface of the chest." She had experienced such hallucinations since the first evening after transfer to our hospital.

On the 4th hospital day, bilateral brachial angiograms demonstrated a right middle cerebral artery (MCA) aneurysm and a right SCA aneurysm

Received April 13, 1987; Accepted January 7, 1991

Author's present address: Y. Harada, M.D., Department of Neurosurgery, Okayama Kyoritsu Hospital, Okayama, Japan. 


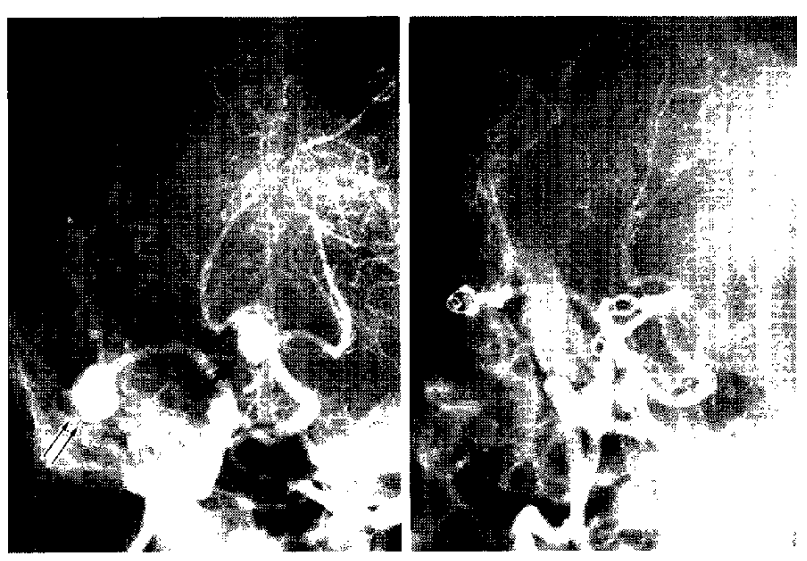

Fig. 1 left: Preoperative bilateral brachial angiogram, anteroposterior view, showing a right MCA aneurysm (double arrow) and a right SCA aneurysm (arrow) with a small bleb (arrowhead). right: Postoperative right brachial angiogram, showing aneurysms clipped at the neck.

(Fig. 1 left). The latter had a small bleb and was considered to have ruptured. Left carotid angiograms performed on the 7 th hospital day was unremarkable.

On the 10th hospital day, she complained of severe headache. Her blood pressure was $150 / 100 \mathrm{mmHg}$. She developed right oculomotor nerve paralysis. The right pupil became mydriatic and did not react to light, and right blephaloptosis developed. She was awake, oriented, and followed commands. The visual fields were normal by the confrontation test. She made no complaint about her vision until the 13th hospital day, when she saw the white ceiling change color from blue to orange. She again recognized it as unreal. No hallucination was described by her thereafter.

Both aneurysmal necks were clipped via a right pterional approach on May 27, 1982 (Fig. 1 right). The SCA aneurysm rupture was confirmed at surgery. Left hemiparesis developed postoperatively. She was alert and well oriented. Ophthalmological examinations including Goldomann's perimetry revealed normal visual fields. Visual acuity was $20 / 20$ bilaterally without correction. Ocular mortility, pupillary reaction, and fundi were normal. She became ambulatory in 3 weeks, and was discharged on the 32nd postoperative day. Four months postoperatively, she was leading a normal life with slight left hemiparesis.

\section{Discussion}

Our patient had visual hallucinations that appeared in the evening and caused insomnia. The hallucinations were vivid, well formed, and always recognized as unreal by the patient. This is similar to previous descriptions of peduncular hallucinosis., ${ }^{1,5)}$ Wellformed visual hallucinations have also been reported with disorders of the visual association cortex, disorders of the temporal lobe, and with purely ocular disorders such as cataracts, glaucoma, and retinal hemorrhage. ${ }^{3)}$ In this patient, because of the normal ophthalmological findings, we diagnosed peduncular hallucinosis.

Peduncular hallucinosis is considered a "top of the basilar" syndrome." In this case, it was the only neurological finding (except anisocoria, which was not considered pathological) at first. Brachial angiography was expected to reveal a "top of the basilar" lesion, but right MCA and right SCA aneurysms were found. The latter was diagnosed radiologically as a ruptured aneurysm, which was confirmed at surgery. Although CT failed to demonstrate a lesion responsible for the hallucinations, the ruptured SCA aneurysm was the probable cause. The hallucinations appeared 2 or 3 days after each of the two aneurysm rupture episodes. This delay suggests that the peduncullar hallucinosis was caused by vasospasm of the perforating arteries to the upper part of the brainstem, rather than direct damage to the brainstem caused by the bleeding.

Peduncullar hallucinosis was previously considered to occur in patients with vascular, inflammatory, and neoplastic lesions near the cerebral peduncles close to the medial aspect of the temporal lobe. ${ }^{2)}$ To our knowledge, peduncular hallucinosis associated with a ruptured aneurysm has not been described before. It is interesting that peduncular hallucinosis may be the only localizing sign of a ruptured aneurysm in the upper part of the posterior circulation.

\section{References}

1) Caplan LA: "Top of the basilar" syndrome. Neurology (Minneap) 30: 72-79, 1980

2) Critchley EMR, Rossall CJ: Hallucinations. $\mathrm{Br} J$ Hosp Med 19: 264-270, 1978

3) Lance JW, Cooper B, Misbach J: Visual hallucinations as a symptom of right parieto-occipital lesions. Proc Aust Assoc Neurol 11: 209-217, 1974

4) Lhermitte J: Syndrome de la calotte du pedoncle cerebral: Les troubles psycho-sensoriels dans les lesions du mesocephale. Rev Neurol (Paris) 38: 13591365,1922 
5) Rozanski J: Peduncular hallucinosis following vertebral angiography. Neurology (Minneap) 2: 341349,1952

6) Van Bogaert L: L'hallucinose pedonculaire. Rev Neurol (Paris) 43: 608-617, 1927
Address reprint requests to: Y. Harada, M.D., Department of Neurosurgery, Okayama Kyoritsu Hospital, 8-10 Akasaka Hon-machi, Okayama 703, Japan. 